\title{
Yvette Centeno: uma poética ao rés do tempo e das coisas sem tempo (Entre Silêncios. Poesia 1961-2018)
}

\section{Resumo:}

Como um mapa desdobrável, dos que exibem com maior ou menor detalhe as possíveis direções e coordenadas dos lugares que se buscam, assim uma (quase) integral obra poética reunida num único volume pode ser lida e estudada sob diferentes perspetivas ou ângulos de incidência: cronológico, temático, simbólico. Preservando a funcionalidade desse olhar multifacetado, a um tempo global e analítico, este ensaio intenta seguir um itinerário de leitura plural e intersecionada do livro de poemas de Yvette K. Centeno, Entre Silêncios. Poesia 19612018. No seu despojamento retórico, nela se dá voz a um conhecimento depurado do mundo feito de incursões afetivas, que vão da dor à alegria, da ironia à revolta, da alusão erótica à inquirição espiritual, da paixão subjetiva ao amor universal, do corpo físico de mulher à consciência política do ser feminino, do sentimento filial ao maternal, do sentido do trágico à esperança redimível. Mas também feito de declinações culturais e literárias que a inscrevem, sem intenções de filiação programática, e com pontuais incursões em língua francesa, no horizonte da tradição lírica erudita em língua portuguesa.

\section{Palavras-chave:}

Lírica contemporânea portuguesa, Yvette Centeno, obra poética, provocação

\section{Abstract:}

Like a fold-out map that displays in more or less detail the possible coordinates of locations of interest, a poet's (almost) complete works collected together in a single volume can be read and analyzed from various perspectives: chronological, thematic, symbolic. The present essay undertakes a multifaceted reading, both global and analytical, of Yvette K. Centeno`s book of poems Between Silences. Poetry 1961 to 2018. In its rhetorical bareness her poetry gives voice to a distilled awareness of the world made of affections, ranging from pain to joy, from irony to rebellion, from erotic allusion to spiritual inquiry, from subjective passion to universal love, from the woman's body to the politics of the feminine being, from filial sentiments to the maternal feelings, from the sense of the tragic to the hope of redemption. However, her poetry also makes cultural and literary references that, albeit without programmatic affiliation and with occasional incursions into the French language, undeniably form part of the Portuguese lyrical tradition 
Keywords:

Portuguese contemporary poetry, Yvette Centeno's complete poetic woks, provocation

Como um mapa desdobrável, dos que exibem com maior ou menor detalhe as possíveis direções e coordenadas dos lugares que se buscam, assim uma (quase) integral obra poética reunida num único volume pode ser lida e estudada sob diferentes perspetivas ou ângulos de incidência: cronológico, temático, simbólico. Preservando a funcionalidade desse olhar multifacetado, a um tempo global e analítico, este ensaio intenta seguir um itinerário de leitura plural e intersecionada do livro de poemas de Yvette K. Centeno, Entre Silêncios. Poesia 1961-2018.

Publicado em 2019 pela editora Glaciar, o seu título, que retoma o que saiu em 1997 na editora Pedra Formosa, fornece a indicação que nele se recolhe o conjunto de livros impressos ao longo de quase seis décadas, do início dos anos sessenta do século XX ao limiar da segunda década do XXI. Dos doze títulos autónomos e constituintes da obra poética da autora - Opus 1 (1961), O Barco na Cidade (1965), Poemas Fracturados (1967), Irreflexões (1974), Sinais (1977), Algol (1979), Perto da Terra (1984), Entre Silêncios (1997), A Oriente (1998), Cancões do Rio Profundo (2004), Outonais (2017), Poemas com Endereço (2015) - a coletânea integra nove, excluindo parcialmente dois da década de setenta, Sinais (1977) e Algol (1979), e o mais recente Outonais. Em tão dilatado segmento temporal é talvez possível identificar no monóstico "Escrever: provocação de mim mesma" (98) uma das pedra angulares da escrita em verso de Yvette Centeno, a que se pode acrescentar o dístico "Escrever - forma de fixação / do que investigo" (idem). Estas são as duas pedras a partir das quais se projeta uma escrita formalmente contida, com a medida ritmicamente acertada à expressão da variedade de respostas que temática e simbolicamente a autora dá às suas (auto) provocações e investigações: as que se representam sob tons e modalidades de um largo espetro de (auto) conhecimento das suas afeções e inteleções transfiguradas em mediações culturais e literárias. Escrita, portanto, à medida de provocações e investigações de vário âmbito e sentido: das mais ligeiramente prosaicas - "Só falam em comida / antes e depois de digerida" (83) - às mais ousadas afirmações e interrogações místicas - "Deus: Aqui, Agora. // Deus procura-se em nós. / (Ou manifesta-se?)" (95) -, passando pela lapidar síntese crítica de leituras eletivas - "Clarice Lispector: Não vejo no ponto a solidão. Vejo só o infinito" (91) -, por assimilações essenciais de conceções filosóficas autoralmente identificadas - "Heidegger: la vérité de l'être / c'est sa réalité" (105) -, por formulações axiomáticas de contundente teor axiológico - "As virtudes separam-nos dos outros / Os defeitos integram-nos" (82), ou de incentivante recorte programático: "Experimentar ideias e palavras" (104).

Na sua enunciação aforística e epigramática, as cento e oitenta e seis "irreflexões", concebidas entre 1961 e 1971, integram um conjunto múltiplo de meditações que, dando corpo ao volume com aquele título, reverberam o programa poético da provocação e investigação da 
autora. Numa leitura global, e não apenas cronológica, do conjunto da obra, Irreflexões e (outros lugares-comuns) tendem a ocupar um lugar central na produção poética de Yvette Centeno, a desempenharem, portanto, uma função charneira entre o sentido globalmente mais irónico, satírico, iconoclasta (provocador), dos três livros publicados até essa data, e o tom tendencialmente mais contemplativo, metafísico, nostálgico (investigador) dos seis que se lhes seguiram. Esta dualidade não se organiza de modo bipolar, não constitui um díptico discretamente articulado na sua autonomia constituinte, mas indicia fases discerníveis na sucessão da escrita poética da autora. É assim que no livro de estreia, Opus 1 (1961), sobrevêm exemplos textuais atravessados de humor, por vezes negro, que têm como foco práticas sociais instituídas, comportamentos legitimados pela moral dominante, gestos mais ou menos reconhecidos como triviais pela força do hábito, mas suscetíveis de serem mordazmente examinados. Veja-se o poema "Pedido de Casamento" composto à maneira de uma cena de teatro do absurdo e para ser lido como um diálogo encadeado entre o pretendente da noiva e o pai desta: "Venho pedir a mão de sua filha / disse o jovem tímido olhando para o chão / Porquê a mão? / Porque é costume / é a tradição / [...] é como deve ser / é convencional / Só não é original / mas seja disse o pai depois de meditar / pode levá-la mas trate-a com cuidado / era de estimação a mão / como pode calcular / O jovem abriu e fechou a boca repetidas as vezes / admirado / enquanto o velho pai que tinha ideias suas / foi buscar a faca da cozinha / e trouxe a mão da filha / sozinha." (26-27). Na sua mordaz e sinistra excentricidade, a rima final do poema, para além de sugerir subtilmente a crítica à função social, reservada tradicionalmente ao género feminino, da mulher doméstica, é um procedimento formal com propósitos lúdicos que, por exemplo, no poema "A Rua", surge exponenciado pelo emparelhamento reiterado dos versos - chão / visão; nevoeiro / tinteiro; mentais / mais; etc. - nas sete estrofes irregulares que o constituem. O jogo com a associação inventiva de ideias desencadeadas pelo efeito rimático dos significantes reforça a intenção satírica e humorística deste poema modulado por recurso a imagens surrealizantes: "Há sinfonias demasiado completas a dançar no ar / (nuar: verbo irregular; eu nuo, tu nuas, ele nua = nudismo geral) / e por toda a parte cavalgam os cavalos de Chagall / transpondo o arco-íris de todo o pensamento / que é realmente mento / porque só pensa é fácil / o difícil é o verdadeiro e completo pensa-mento // No restaurante há omeletas em chamas / servidas por bombeiros voluntários / e as banheiras estão cheias de afogados mentais // A lápide de inscrição no cemitério diz apenas / a vida não deu pra mais" (27-28). O jogo com as cacofonias - no ar / nuar -, que amplia o sentido jocoso dos versos e das suas diatribes anti convencionais, ocorre deliberadamente também em "Natal", um poema-caricatura, destituído de qualquer solenidade espiritual, da festa gastronómica da consoada em que sobressaem os gestos dos comensais tutelados pela autoridade digestiva do patriarca: "O chefe de família limpou a boca ao guardanapo e afirmou / assim como dois e dois são quatro e não são outra coisa / O Natal é o Natal e não é outra coisa antes pelo contrário [...] / À volta da mesa metade da família discutia a mensagem e comia / e a outra metade mais intelectual comia a mensagem / e discutia / sim tal não tal / não tal / Natal" (30). Esta subversão das práticas liturgicamente consagradas, dos ícones religiosamente cultuados, dos arquétipos e mitos idealizados intensifica-se em vários poemas e, na radical inversão simbólica do seu 
Cadernos de Literatura Comparada

Yvette Centeno: Uma poética ao rés do tempo e das coisas sem tempo

significado espiritual, dá mesmo lugar a uma representação antitética focada na latente carga erótica da sua incarnação material. A alusão erotizada de motivos originariamente inscritos na esfera do sagrado, ou a ela associados pela sua mundana institucionalização surge, em versos de poemas de Opus 1, como "Sagração" - e. g. "e de novo os dois foram um só voltados para dentro" (32), "O mito descoberto" - e.g. "Esféricos felizes e completos / sol terra e lua intervenção divina /Eros /Eros" (34) - "A virgem" - e.g. "E veio procurar nos homens / o verdadeiro mar" (36); mas também em textos de Poemas Fracturados, como "A Tentação de Santo António" - "Tem sempre um corvo / em cima da cabeça / que lhe devora os olhos / ternamente / e lhe transforma o cérebro / [...] / e faz correr por dentro / o fio do desejo / liquefeito" (61), ou ainda em "Sobre a morte de um Papa" - " o corpo foi colocado em câmara ardente aberta ao público. / [...] / Caiu de noite / a chuva / sobre o corpo / gelado / indiferente / em pequenos espasmos / de gotas / sexuais" (64).

À dimensão lúdica, jocosa, subversiva de vários textos de Opus 1, sucedem-se os de teor globalmente mais disfóricos em o Barco na Cidade (1965), título com valor de oxímoro, que remete para a ideia paradoxal ou imagem disruptiva de um veículo imobilizado e deslocado (o barco) pela sua total inequação ao meio físico em que se situa (a cidade), mas também em Poemas Fracturados. Neles parece aflorar uma experiência do mundo em que à irónica desconstrução das suas automáticas e inconscientes práticas sociais, representados pela conduta alienada dos "magros do infinito" (40;43), se sobrepõe o conhecimento inelutável do seu lado sombrio. Em "A multiplicação do peixes" e "Os peixes", da breve sequência com esse título inserida em $O$ Barco da Cidade, damo-nos conta da alegorização satírica de reduzir a espécie humana à condição piscícola de cardume, de a caricaturar como coletivo despersonalizado no agenciar uniforme dos seus comportamentos acéfalos: "Estão sentados no chão sem movimento. / Multiplicados entre si até ao infinito / os peixes uniformes já não se reconhecem / porque perderam a mancha de coral" (42). A perda da identidade pessoal, da sua singularidade anímica, volitiva - "a mancha de coral" - surge representada como um efeito da propagação invasiva da natureza-peixe e da sua contaminante metamorfose em natureza-humana, desvitalizada, amorfa, fantasmagórica, disforme, desalmada: "Os peixes reunidos da cidade / invadiram as ruas e as casas / e as cabeças dos homens / e pouco a pouco foram murchando a vida / nos momentos de amor [...] / peixes em fila indiana / em bichas de autocarro / peixes de mãos balofas / e de olhos de vidro circular / peixes barrigas / recheados de si próprios / e de restos de homens mutilados / peixes iguais / cinzentos metálicos armados / mecânicos / monótonos / mortais (41-42). A cidade é, nesta série de poemas, o grande lugar distópico - " A cidade é um buraco negro / geométrico / perfeito / grande guerra" (46) -, o cenário desencantado e do desencontro, da regressão - "Nasceu o homem verde / o homem planta / o homem vegetal / feito com as horas mortas / da antiga cidade natural" (47) - e da suspensão das formas e dos volumes, das ações e interações razoáveis e inteligíveis - "A rua é branca e fria / e os homens e as mulheres são jovens e gritantes / e todos riem / mas não se passa nada / porque o seu riso não é / como era dantes" (46). A cidade encalhada como um barco destroçado figura-se aqui como o espaço do pesadelo e da contrafação. O recurso a imagens sincopadas e ásperas dá consistência 
e expressão a esta atmosfera soturna, depressiva, a ponto desta contaminar e se distender, em alguns poemas, à auto representação de um sujeito lírico exangue e doído, reflexo interior dessa polis de pesadume e sombras: "Eu tenho em mim / uma cidade antiga / com uma rua aberta / uma rua ferida / [...] / tenho neste momento / o meu amor sem vida" (50). É nesse registo de dramatização subjetiva que se conclui o livro, e, no seu balanço evocativo, o último poema "Autobiografia", figurando uma decomposição necessária como condição de abertura a outras possibilidades existenciais e literárias, constitui-se numa síntese anunciadora, simultaneamente, de fim e princípio de ciclo : "Depois disso agarrei no ponteiro das horas. / Uma pancada seca na cabeça. / Fim. / Lembro-me ainda que saí / deixando a porta aberta atrás de mim" (57).

A emergência do eu lírico sobressai com maior nitidez no livro seguinte, Poemas Fracturados (1967). Embora também neles circule a linguagem da irrisão e de alguma desesperança - e.g. "esbarra-se nas palavras / cai-se pelas palavras dentro / da inutilidade // e há sempre um momento em que se vê que é tarde / e não valeu a pena" (66) -, é com maior frequência que se escuta a voz recortada da subjetividade em variadas escalas de entoação: da íntima expetativa e renovação afetiva - "Já guardei tudo o que ficou de ti. / Vou construir-te agora / de novo / no caminho" (63) - à tenaz, serena, paciente e indefinida esperança sem fim - "Espero / sentada / tranquilamente em mim / [...] Espero / mesmo que tenha de ficar / aqui / sentada / eternamente" (63-64); mas também do erotismo síncrono - "gosto / da chuva / assim // dormente / reflexo / de um movimento / de amor / exterior / a mim" (69) -, da transfiguração onírica - "Saio do corpo no limiar do sono / e viajo / percorro o espaço / de fora / e de dentro" (73); mas também da voz que sofisticadamente se embala, aprende e se transforma com a poética de outrem, como sucede no último dos três breves poemas metaliterariamente intitulados e construídos a partir da escrita de Herberto Helder: "Dizia sangue / a tua voz dentro / dizia sangue / como a chamar por mim / e eu levantei-me / saí da noite / e empurrei a pedra / e percorri as veias que faltavam / para chegar ao fim" (65). Deste conjunto de textos, irradiando ou convergindo para um eu multímodo, o que mais evidentemente adere às flutuações e síncopes do ser no tempo é o que, jogando com o recurso à personificação, leva por título "As horas". É um poema que, com gravidade existencial e distanciamento lúdico, desfila situações e estados mais ou menos solenes e burlescos de consciência, que ganham corpo na justa medida em que surgem subordinados ao devorador deus cronos e ao seu severo modo de produção do tempo, de quem, com algum humor, o sujeito lírico aspira a se libertar: "O apito da fábrica divide a minha noite / numa série metálica de horas / desfilando no espaço / umas atrás das outras / horas de todos os feitios / e cores / e tamanhos / [...] horas vivas / e horas mortas / horas muito direitas / e muito formais / completamente vestidas de preto [...] // e as horinhas / pequenas e perdidas / sempre a correr atrás / alucinadamente / gritando / pai e mãe / e mãe e pai / esperem esperem por nós / não nos deixem ficar // ah por favor / calem-me esse apito! // deixem-me dormir em paz!" (70; 72-3).

Os mais breves poemas de toda a produção lírica de Yvette Centeno, a maioria dísticos, alguns monósticos, mas também tercetos, quadras, e raramente textos com mais de uma estrofe, foram publicados em Irreflexões (1974), livro que acima considerámos ocupar um lugar 
central, de transição, entre duas discerníveis, se bem que genéricas, fases na distribuição dos títulos da sua obra poética. O relativamente longo período a que se reporta a produção destes textos, de 1961 a 1971, o seu largo campo temático aliado à economia de meios verbais que lhe servem de suporte, do dictum sagaz - "As virtudes separam-nos dos outros. / os defeitos integram-nos" (82) - à subversão da doxa - "Moral? / Não é Deus, é o homem / que está cheio de zonas interditas" (98) -, do aforismo filosofante - "Homem: desejo de permanência" (98) - à síntese poética - Michaux: / Ce grouiellement de forces / dans la tête" (107) -, do juízo crítico-satírico - "Portugal: / país em que o bom senso espanta / Um país pequenino / com gente à sua medida" (84) - e à inquirição subversiva espiritual - "A essência de Deus é feminina. // Deus mãe / primeiro princípio criador" (86) -, parecem testemunhar um compromisso da autora em cultivar este modo literário no limite das suas depuradas e sublimadas possibilidades estéticas - estratégia retórica que retomará posteriormente em A Oriente.

Em Perto da Terra (1984) intensifica-se a voz subjetiva e a vivência identitária do feminino. Na primeira seç̧ão do livro, Conjunção, prevalece um tom amargurado, quase fatalista sobre a vocação servil do corpo da mulher potencialmente reduzido, na sua função biológica procriadora, à dupla e paradoxal condição de manancial e cárcere, ou até mesmo de patíbulo - "quando o ventre é o mar / quando o ventre é a água / salgada / numa boca / quando o ventre é a fonte / quando o ventre é a forca" (111). Mas é também a tomada de consciência desse corpo assertivo e auto determinado, que serve ambiguamente de pronúncio à rebelião contra a dependente função social da mulher doméstica e da afirmação da sua liberdade sexual - "a servidão da casa / a servidão da cama / quem te disse mulher / que toda a servidão / se pode transformar / em chama?" (113). A esta intensificação da natureza ambivalente do corpo feminino como lugar de prisão social ou centro erótico da paixão física agrega-se a expressão de sentimentos de sofrido despeito amoroso - "eu avançava ao contrário / dentro de ti me perdia" (113) - , mas também de júbilo passional - "quem te ensinou a amar / [...] quem te ensinou a desfazer / todos os nós de um corpo / abrindo-o devagar" (118). São estes textos de autognose do ser feminino, a um tempo dilacerados e exultantes - "dá-me vinho meu amor / dá-me vinho / vinho pela tua boca" (126) - , replicados nas duas outras secções O que Sou Eu e na que leva por título o do próprio livro, que dão fundamento à metáfora e estabelecem a analogia do corpo da mulher com a natureza sólida e polimórfica do elemento terra: "também a terra / tem o seus cabelos / que no Verão / penteia / longamente // também a terra / espera / que a contemplem // a terra / é um a mulher / tem um corpo / que sente" (128).

Se em Perto da Terra as linhas do discurso se centram num sujeito que, auto revelando-se na inquirição de um si feminino, vivencia estados de afeção polarizados e de cisão dorida com a experiência da relação íntima - "de todos os teus abraços / fiz cavalos // e ao dizer-te adeus / soltei-os contra o tempo" (124) -, a ponto de questionar abruptamente a neurótica representação masculina da imagem da mulher - "a grande mãe / a grande prostituta / o homem que a procura / não sabe o que lhe quer" (117) -, em Entre Silêncios (1997) abre-se o espaço poético a um sujeito que evoca lugares revisitados e mediados pelo uso da memória afetiva e cultural. As cinco partes que integram este livro, a última delas com o seu título, têm em comum 
exibirem a vontade de reificar a lembrança, de a converter em coisa e de a declinar, sem o peso de uma irredutível singularidade funcional e semântica, sob diferentes associações de sentido, pessoal, urbano, cosmopolita, literário. Assim se ordenam poemas tematicamente variados e subordinados a seç̧ões do livro com títulos como "O Nome das Coisas", "Coisas de Santiago", "Coisas de Macau", "Coisas da Catalunha", "Coisas de Berlim". O uso do plural e das maiúsculas - "Coisas" - expande, ramifica, integra, multiplica significados que dissipam e esbatem, sem anular, o pendor rememorativo dos textos, segundo a lição de que "saber as coisas / não é / saber o seu nome: / o nó que as prende / a espuma / que as revolve" (156). Por isso as coisas de Berlim são "folhas douradas do jardim" (144), são "vozes esparsas / como nuvens no céu / que o vento afasta" (idem), são "choupos dobrados sobre o rio / lágrimas que não correm" (idem) , são nomes de artistas, Gerhard Bohmer - "O Anjo com o seu joguete: o homem" (145) - e Heiner Müller - "não há inocentes no mundo / e em breve tão-pouco haverá mundo / esta a lição de Müller" (idem) -, mas são também a Berlin-Brandenburg, atravessada sem o solene respeito pelo seu simbolismo histórico, apenas na pesarosa companhia das sombras inaudíveis do passado - "Atravesso o portão / caminho sob as tílias / uma sombra a meu lado / de tantas outras sombras / rodeada / não oiço o que ela diz" (145). As coisas são ainda a Literaturhaus (Casa da Literatura), um lugar que serve de pretexto não a alusivas citações eruditas sobre o valor de conhecimento da literatura mas a uma dramatizada autopsicografia com origem num sentimento de estranheza espacial e numa cindida e assumidamente imperdoável vontade de negação de si e de obliteração do livro que é o mundo: "longe é o nome / do espaço a que pertenço [...] / vejo o meu rosto / espelhando-se nos vidros / estou ali / e não estou / já não me reconheço / pois é sangue a ferrugem / das copas que me atraem / é negação / o murmúrio da fonte / é som / do esquecimento // Esquecer não tem perdão" (146). Daí que a tarefa de quem procura a redenção, a dolorosa liberdade de reconhecer tudo o que foi e aconteceu, seja a de desfiar o "novelo // de pequenas artérias / rebentadas // por ali / escorre / a memória // a pulsação que dói // quem não recorda / não vive // não desenrola / o fio / que redime" (150). Alguns dos poemas e linhas que compõem a série de "Entre silêncios" parecem desfiar esse ténue fio redentor que não ilude o pesadume ou mesmo a crueza do ser e da sua qualidade trágica, tal como se pode ler em "Homenagem a René Char" - "Talhavas / as palavras / no coração da pedra / sangrando / o seu perfume" (152). É um fio que parece soltar-se por efeito da persistência, sem a qual não há renascer nem encontro com a figura libertadora - "Caminhou / caminhou / pelo túnel profundo // no caminho encontrou / a bruxa Lorelei // seu cabelo era de ouro / sua voz de prata // o seu corpo formava a bola azul do mundo" (151). É um fio imprevisível, que pode irromper como uma epifania no curso do tempo - "Estão contadas as horas // Eram tantas / que as contaram à pressa / e caiu uma:/ pulsação de cristal / aspirando a ser / estrela" (152) -, mas também em consequência de um gesto libertador, de superação da dualidade da alma, representada alegoricamente, por reenvio ao Fedro de Platão, por dois cavalos: "Esses cavalos da alma / de cloisonné ou de jade / vejo-os também em Bruxelas / e recordo os de Paris: dois na sala de jantar / sobre o armário fechado / e um no teu quadro a óleo / voando pela janela / buscando o espaço feliz." (148). 
Cadernos de Literatura Comparada

Yvette Centeno: Uma poética ao rés do tempo e das coisas sem tempo

A Oriente (1998) não é propriamente um título que procure insinuar a representação do lugar mítico ou exótico da busca da felicidade, justificando-se, antes, pela dominante conceção formal dos seus oitenta textos, à maneira das composições poéticas japonesas dos haikais, que o integram. Todavia, o vigésimo sétimo diz: "Horizonte feliz: / céu e mar confundidos" (172). Neste livro, que recolhe alguns textos de outros dois, Sinais (1977) e Algol (1979), o tópico da felicidade é poeticamente elaborado quer como a consequência de uma prática criativa, não solipsista, as duas premissas para a sua inevitável manifestação conclusiva - "Is s'agit d'être ensemble / ils s'agit de créer / il s'sagit d'être heureux."(160), quer como uma interrogação especulativa sobre uma possibilidade ontológica post mortem: "Agora que já dormes / há rios no teu sono, / há mar? // Passeias na praia longínqua / páras nalgum rochedo // vês os montes / a serra // sopras a flor das amendoeiras / como se fosses vento // apanhas camélias brancas // enfeitas o cabelo // és feliz / na noite dos tempos?" (161). Os três versos de métrica livre e variável dos haikais de A Oriente, opção formal que é aliás retomada, apesar de antecedida por títulos, na primeira sequência de Poemas com Endereço, dão corpo ao registo de pensamentos, ideias, registos de situações e momentos que, na sua brevidade, jogam com o efeito da sugestão e abrem, como é prescrito pelas normas de composição dessa poética emanada do espírito zen, amplas possibilidades de interpretação: "Águas bravas / rochedos, / covas" (178), ou "No refluir da água, / redescobrir / o rosto" (171), ou ainda "Vozes ao fim da tarde: / desencontros / mortes que se receiam" (170).

A temática da morte surge pelo menos em sete poemas de A Oriente $(12,14,15,25,33,35,79)$ e tornar-se-á recorrente nos dois livros posteriores, Canções do Rio Profundo (2004), e Poemas Com Endereço (2015) e suas respetivas seç̧ões. Assim sucede em Canções para R. C., do primeiro daqueles dois livros. O sentido elegíaco dessas oito canções inspiradas no universo afetivo da autora articula-se em torno da evocação do passamento lúcido de R. C. - "Com uma ruga / interrogaste a morte // sem desviar os olhos / viste-a lançar os dados / e decidir a sorte" (185) -, mas a ideia da indissolúvel ligação, temporalmente diferida, entre o sujeito poético e o seu destinatário é também antevista como inevitável e teleologicamente necessária: "Sei que me esperas / e devagar / vou indo ao teu encontro // num corredor de luz / numa cama de treva. // Suspenderam o tempo / e alguém está a fechar / o espaço / que me deram." (187). A este poema parece responder um outro da série de Canções do Rio Profundo, "Abdicação" - em que o sujeito poético, evocando a imagem shakespeariana de uma Ofélia apaziguada na morte, se auto representa no lugar eletivo, não iniciático ou portador de qualquer indício do mal, em que desejaria expirar: "Aceito morrer em breve / mas não irei ter contigo / às salinhas escuras / por onde tens andado / ficando à espera. // Também não quero o mar / nem a montanha / locais de iniciação / Quero um regato ameno / de água fina correndo / por entre arbustos rasteiros // E então ao longe / a figueira / de folhas enganadoras // com uma sombra que oculta / o gesto da maldição." (202). A qualidade elegíaca das canções culmina mesmo numa espécie de representação personificada da lei do eterno retorno, a da ressurreição memorial de R. C. distendida à reconstituição da sua infância, das suas raízes identitárias, da sua relação filial, das suas brincadeiras com a ideia de morte: "Não repousas na terra / em que foste deixada. // Buscas a pátria antiga / a tua 
casa de infância / os lanches à lareira / o cheiro a pão cozido // o avental da mãe / tua mortalha antiga / quando a brincar / fingias teres morrido." (187). Nas três sequências de poemas que integram as Canções do Rio Profundo sobreleva a temática polissémica da morte declinada sob a forma de luto por uma perda afetiva e íntima ("Cancões para R. C."), em fantasmática projeção onírica ("Sonhos I", "II", III"), pela sua impessoal e universal qualidade simbólica ("Nas Ruas de Lisboa", "Tarot", "Requiem"), em ressonante figuração histórica e cultural ("Trovas da Bela Inês"). O rio profundo é assim o rio da morte sem fim, é o fluxo da cessação da vida subordinada à lei do tempo, é o devir da incessante transformação de tudo o que é.

Poemas com Endereço, o último da coletânea, inclui textos escritos ao longo de oito anos (2010-2018) e nele alguns dos seus destinatários são explicitamente nomeados como se uma das principais razões de ser da poética da autora radicasse na assumida e renovada vontade de a vincular ao princípio da amizade personificada, à cumplicidade mediada pelo valor da representação literária do encontro com a vida compartilhada e amorável. A expressão maior da verdade dessa amizade incondicional decorre da evidência de alguns dos seus destinatários nunca terem lido ou poderem vir a ler os poemas que lhes são dedicados por terem sido escritos a título póstumo. Neles se celebra a persona, a um tempo sugerida e transfigurada, de quem partiu, associada quer ao espaço em que decorreu a sua vida ("Fui feliz naquela casa" - Ao João Eduardo, in memoriam), quer ao reconhecimento do traço fundamental de uma poética pessoal ("Balada da infância feliz" - Ao António Ramos Rosa, in memoriam), quer às experiências culturais, intelectual e afetivamente partilhadas ("Os abutres" - Ao Herberto Helder, in memoriam), quer ainda ao esboço de reconstituição de uma irredutível singularidade individual, tal como sucede no poema "Puer Eternus / O Sol", dedicado à memória de Bernardo Sassetti : "Vive dentro dele / uma criança // ele era a casa // a criança fugia / correndo para o sol // e ele corria atrás dela: / o sol queimará as tuas asas! // - regressa! // - regressa a casa! // Mas já as cinzas douradas / caíam sobre a estrada" (210).

Em contraponto com este lutuoso culto da amizade, outros poemas com endereço celebram o tópico da plenitude da vida, a esperança dela se cumprir no fluxo da sua indómita corrente juvenil - "descobriu o que é a vida: / é uma areia infinita // escolhe agora a sua onda / numa praia favorita" (213) -, na dissipação das suas inevitáveis agruras - "Le soleil chasse l'ombre / l'enfant s'endort tranquille / bientôt le jour viendra ..." (211) - e na aspiração a se personificar numa axiologia de "pensamento inteiro: Belo, Bom, Verdadeiro" (212). São disso exemplo "Chanson pour mes petits-enfants" "Às minhas netas cavaleiras", "À Veroca no seu aniversário", cuja composição, apesar de inspirada, como se infere dos títulos, no círculo familiar da autora, é motivada e elaborada sob o signo da confiança nas possibilidades solares e órficas da vida: "Vão em cavalos alados: / cavalgam nuvens e ventos / são cavalos-pensamento / de crina bem entrançada / pelo negro bem escovado / cascos lavados, ligeiros / e que atravessam o tempo ..." (idem). No conjunto dos poemas que sobrelevam de uma consciência dramática, pesarosa e sofrida da vida, o mito de Orfeu é assim convocado para simbolizar o desvanecer do medo cósmico - "vinha da treva escura / parou junto ao portão / com a chuva no cabelo / e uma luz no olhar / que repelia o medo" (227) - , a desordem da cólera - "a sua música paira no ar / atrapalhando 
Cadernos de Literatura Comparada

Yvette Centeno: Uma poética ao rés do tempo e das coisas sem tempo

a dança / das Ménades furiosas" (228) - , o triunfo sobre o tempo e o seu desengano: "Orfeu não morre nunca / na sua música permanece / a esperança" (idem).

À semelhança dos seus livros anteriores, a poética cultivada por Yvette Centeno em Poemas com Endereço segue uma contida medida verbal de suporte a um conjunto largo e variado de ideias e temas que denotam os seus múltiplos interesses culturais e as suas inquietações políticas e existenciais. É assim que, seguindo um movimento de escrita impelido pela exigente atenção ao valor sonoro do ritmo e à sua livre determinação na composição supra pessoal do texto e dos seus possíveis sentidos - "escrevo quando a palavra ocorre / quando a palavra / escolhe / ou escorre / e por dentro me / acolhe" (255) -, se alinham poemas que fixam imagens simbólicas, por vezes narrativamente elaboradas, de acontecimentos dramáticos e motivadores de um sentimento empático de denúncia pela sua excruciante injustiça - Toda a criança assustada / é criança judia / é criança de Gaza [...] toda a criança assustada / nas forcas deste mundo / é mais um nó ..." (245) - ou tendo como pretexto a vontade de comunicar uma alusiva combinação de ideias sugeridas pelas ideias ou ações representativas de eletivas personalidades históricas, como as do alquimista isabelino John Dee ou as do filósofo contemporâneo espiritual Krishnamurti: "E o tempo? // No Tempo não cabe a vida / a vida que foi vivida / a que está sendo e será // a velhice não redimida ... // diz ele na sua velhice / já tão frágil / e a caminho / meditem esta palavra / esta palavra e ela só: // o Ser é o que é / no Tempo // tudo o mais / apenas Medo" ( 265). Livro de síntese, Poemas com Endereço acolhe ainda raros textos com sentido irónico e.g. "As Almas e as Pratas" - mas em que o dominante traço da nostalgia serve de pretexto a evocações de lugares - e.g. "Junto ao Rio Wey" -, mas também a breves anotações líricas - e.g. "Amendoeiras" - e a uma surpreendente recriação do imaginário e da poética medieval trovadoresca, tal como sucede "Na margem do Rio Gilão: Na margem do rio / aguardando o Amigo / aguardando o Amado // Na margem do rio / penteando o cabelo // Na margem do rio / o Amigo tardando / O Amigo não veio // Na margem do rio / com o pente dourado" (235). Por fim neste livro convergem ainda dois temas com valor de símbolo que refletem dois polos da poética de Yvette Centeno, o da mulher-mãe, que pode ser a mãe universal e a mãe de sangue, e o do enigmático anjo, que pode ser o anjo íntimo, secreto, ou o anjo da história. Mais do que desenharem uma antítese de significados simbólicos ou de irredutíveis vetores semânticos apontando para a disjunção entre o imanente e o transcendente, o que nas suas várias modulações essas figuras também significam é a declinação da tangível e etérea representação dos arcanos da vida e, na sua possível síntese, a do amparo incondicional a que sejam prosseguidos sem fim - tal como se pode ler neste poema de Canções do Rio Profundo: "Difícil é o caminho / que as Mães rasgam. // Vão como se fossem Anjos / mas sem asas." (189).

Lida no seu conjunto, a poesia que Yvette Centeno foi publicando ao longo de mais de meio século, e reunida Entre Silêncios, é singularmente pródiga em pensamento e ritmo, em imaginação e sobriedade de meios expressivos. No seu despojamento retórico, nela se dá voz a um conhecimento depurado do mundo feito de incursões afetivas, que vão da dor à alegria, da ironia à revolta, da alusão erótica à inquirição espiritual, da paixão subjetiva ao amor universal, do corpo físico de mulher à consciência política do ser feminino, do sentimento filial ao maternal, 
do sentido do trágico à esperança redimível, Mas também feito de declinações culturais e literárias que a inscrevem, sem intenções de filiação programática, e com pontuais incursões em língua francesa, no horizonte da tradição lírica erudita em língua portuguesa: a que se renova e se prolonga com a consciência de que pisar um legado antigo feito de palavras e muitas vozes peregrinas é sobretudo um ato de compassiva e infinita inquirição - simbolicamente ilustrado pelo poema "Santiago de Compostela": "No caminho / que pisas / qual o rasto / que deixas / de estrelas / ou de sangue // De quanta gente / levas contigo / as queixas / De quanta gente / o corpo / luminoso ou exangue" (167).

\section{NOTA}

* José Eduardo Reis é professor associado na Universidade Trás-os-Montes e Alto Douro (UTAD) onde leciona na área dos estudos literários. É investigador do Instituto Literatura Comparada Margarida Losa (ILCML) da Faculdade Letras da Universidade do Porto (FLUP) onde tem prosseguido investigação comparatista com ênfase nos estudos literários e culturais sobre a utopia. É mestre em estudos literários comparados com uma tese sobre a influência de Schopenhauer na obra literária de Jorge Luís Borges e doutor em literatura comparada com uma dissertação sobre o espírito da utopia nas culturas literárias portuguesa e inglesa (FCG/FCT, 2007). É autor de vários artigos em revistas especializadas (30), ensaios e capítulos de livros (21), editor de duas utopias literárias portuguesas, Irmânia de Ângelo Jorge (2003) e Redenção de Amílcar de Sousa (2011), co-editor de Nowhere, Somewhere (2006), e de Utopian Foodways: Critical Essays (2019,) Co-organizador do $\mathrm{n}^{0} 36$, Utopia e alimentação, dos Cadernos de Literatura Comparada (2017), do livro Os Médicos de "O Vegetariano" (2019). É membro do corpo editorial das revistas académicas Letras Vivas, Nova Águia, Cultura entre Culturas e Atlante.É membro do conselho consultivo internacional das Obras Pioneiras da Cultura Portuguesa e membro da Comissão Internacional da História Global da Literatura Portuguesa (HGLP). Peer-review das revistas académicas Utopian Studies (Penn State University Press), Cadernos de LIteratura Comparada (FLUP), Vista Panorâmica (FLUP), Revista da APEAA Op. Cit. Em 2011 foi professor visitante do departamento de estudos românicos e germânicos da Universidade de Nova Deli (Índia). 